\title{
GCS as a predictor of mortality in patients with traumatic inferior vena cava injuries: a retrospective review of 16 cases
}

\author{
Michael Cudworth ${ }^{1 *}$, Angelo Fulle ${ }^{1}$, Juan P Ramos ${ }^{1}$ and Ivette Arriagada ${ }^{2}$
}

\begin{abstract}
Introduction: Recent research has determined Glasgow Coma Scale (GCS) to be an independent predictor of mortality in patients with traumatic inferior vena cava (IVC) injuries. The aim of this study was to evaluate the use of GCS, as well as other factors previously described as determinants of mortality, in a cohort of patients presenting with traumatic IVC lesions.

Methods: A 7-year retrospective review was undertaken of all trauma patients presenting to a tertiary care trauma center with trauma related IVC lesions. Factors described in the literature as associated with mortality were assessed with univariate analysis. ANOVA analysis of variance was used to compare means for continuous variables; dichotomous variables were assessed with Fischer's exact test. Logistic regression was performed on significant variables to assess determinants of mortality.

Results: Sixteen patients with traumatic IVC injuries were identified, from January 2005 to December 2011. Six patients died (mortality, 37.5\%); the mechanism of injury was blunt in one case (6.2\%) and penetrating in the 15 others (93.7\%). Seven patients underwent thoracotomy in the operating room (OR) to obtain vascular control (43.7\%). Upon univariate analysis, non-survivors were significantly more likely than survivors to have lower mean arterial pressures (MAP) in the emergency room (ER) (45.6+/- 8.6 vs. $76.5+/-25.4, p=0.013)$, a lower GCS (8.1 +/- 4.1 vs. $14+/-2.8, p=0.004$ ), more severe injuries (ISS $60.3+/-3.5$ vs $28.7+/-22.9, p=0.0006$ ), have undergone thoracotomy $(83.3 \%$ vs. $16.6 \%, p=0.024)$, and have a shorter operative time $(105+/-59.8 \mathrm{~min}$ vs $189+/-65.3 \mathrm{~min}$, $p=0.022)$. Logistic regression analysis revealed GCS as a significant inverse determinant of mortality $(O R=0.6,0.46-0.95$, $p=0.026)$. Other determinants of mortality by logistic regression were thoracotomy $(O R=20,1.4-282.4, p=0.027)$, and caval ligation as operative management $(O R=45,2.28-885.6, p=0.012)$.
\end{abstract}

Conclusions: GCS, the need to undergo thoracotomy, and caval ligation as operative management are significant predictors of mortality in patients with traumatic IVC injuries.

Keywords: Vascular, Trauma, Inferior vena cava, Glasgow, Injury

\section{Introduction}

Traumatic inferior vena cava (IVC) lesions represent $30 \%$ to $40 \%$ of trauma related abdominal vascular injuries [1-4]. In spite of significant advances in pre-hospital care, surgical technique, and surgical critical care, traumatic IVC lesions continue to carry a high overall mortality of $43 \%$ [1,5-11]. Roughly $30 \%$ to $50 \%$ of patients sustaining traumatic IVC injuries will die of their injuries before

\footnotetext{
* Correspondence: mcudworth@gmail.com

${ }^{1}$ Adult Emergency Services, Surgery, Hospital Dr. Sotero del Rio, Concha y

Toro, 3459 Puente Alto, Santiago, Chile

Full list of author information is available at the end of the article
}

reaching a hospital $[1,5-7,9,11,12]$. Of those patients that survive long enough to be hospitalized, another $30 \%$ to $50 \%$ will decease in spite of surgical therapy and resuscitation efforts [13-15]. Penetrating trauma is the cause of $86 \%$ of IVC injuries, with blunt trauma causing only $14 \%$ of IVC injuries [1,5,7-10,14,16-18]. The IVC is anatomically divided into five segments: infra-renal (IRIVC), para-renal (PRIVC), supra-renal (SRIVC), retro-hepatic (RHIVC), and supra-hepatic (SHIVC). Overall, the most frequently injured segment is the IRIVC (39\%), followed by the RHIVC (19\%), SRIVC (18\%), PRIVC (17\%), and the 
SHIVC (7\%) [1,5,7-10,14,16-18]. Numerous studies have analyzed factors associated with mortality in IVC lesions. Factors predictive of mortality reported include level of the IVC injury, hemodynamic status on arrival, number of associated injuries, blood loss and transfusional requirements, among others [1,5,7-10,14,16-18]. Recent work by Huerta el al described Glasgow Coma Scale (GCS) as an independent predictor of mortality in IVC trauma [5]. The aim of this study was to assess GCS, as well as other factors previously described as determinants of mortality, in a cohort of patients presenting with traumatic IVC lesions at an urban tertiary care trauma center.

\section{Methods}

Approval for this study was obtained from the Hospital's ethics committee. A retrospective chart review was performed from January 2005 to December 2011, of all abdominal vascular trauma patients presenting to the tertiary care trauma center at Hospital Dr. Sotero del Rio. Patients that died before operative intervention or pronounced dead on arrival were excluded. All patient charts were individually reviewed for the following parameters: demographic data, Injury Severity Score (ISS), initial systolic blood pressure in the ED (SBP), initial diastolic blood pressure in the ED (DBP), initial heart rate in the ED, admission base deficit expressed as base excess (BE), time in the ED prior to operative intervention, and GCS as determined by a chief resident or the most senior attending trauma surgeon in the trauma bay. Operative records were reviewed for mechanism and location of IVC injury, the number of associated injuries encountered, the method of vascular control and repair, the need for thoracotomy for vascular control, transfusional

Table 1 Distribution of associated injuries between groups

\begin{tabular}{lccc}
\hline & $\begin{array}{c}\text { Survivors } \\
(\mathbf{n}=10)\end{array}$ & $\begin{array}{c}\text { Non-survivors } \\
(\mathbf{n}=6)\end{array}$ & P value* \\
\hline Gastric & $1(10 \%)$ & $1(16 \%)$ & NS \\
Duodenum & $2(20 \%)$ & $1(16 \%)$ & NS \\
Small bowel & $4(40 \%)$ & $2(33 \%)$ & NS \\
Large bowel & $1(10 \%)$ & $1(16 \%)$ & NS \\
Spleen & $1(10 \%)$ & $1(16 \%)$ & NS \\
Kidney & $3(30 \%)$ & $2(33 \%)$ & NS \\
Liver & $2(20 \%)$ & $1(16 \%)$ & NS \\
Pancreas & $1(10 \%)$ & $1(16 \%)$ & NS \\
Lung & $1(10 \%)$ & $1(16 \%)$ & NS \\
Diaphragm & $0(0 \%)$ & $1(16 \%)$ & NS \\
Cardiac & $2(20 \%)$ & $0(0 \%)$ & NS \\
Aorta & $0(0 \%)$ & $3(50 \%)$ & NS \\
Superior mesenteric artery & $0(0 \%)$ & $1(16 \%)$ & NS \\
Splenic or iliac vein & $1(10 \%)$ & $1(16 \%)$ & NS \\
\hline
\end{tabular}

${ }^{*} N S$, not significant.
Table 2 Significant differences between groups

\begin{tabular}{lccc}
\hline & $\begin{array}{c}\text { Survivors } \\
(\mathbf{n}=\mathbf{1 0})\end{array}$ & $\begin{array}{c}\text { Nonsurvivors } \\
(\mathbf{n}=\mathbf{6})\end{array}$ & P value \\
\hline ER MAP (mmHg) & $76.5+/-25.4$ & $45.6+/-8.6$ & $0.013^{*}$ \\
GCS & $14+/-2.8$ & $8.17+/-4.1$ & $0.004^{*}$ \\
Operative time (min) & $189+/-65.3$ & $105+/-59.8$ & $0.022^{*}$ \\
ISS & $28.7+/-3.5$ & $60.3+/-22.9$ & $0.0006^{*}$ \\
OR thoracotomy & $20 \%$ & $83.3 \%$ & $0.024+$ \\
\hline
\end{tabular}

*Oneway ANOVA analysis of variance.

+ Fischer's exact test.

requirements, and operative time. Other data assessed included length of hospital stay. Statistical analysis was performed with STATA 12.1 (Stata Corp LP, College Station, TX). Data is represented as means +/- SE for univariate and logistic regression analysis, and means $+/-$ SD for oneway ANOVA analysis of variance. $P$ values of less than 0.05 were considered significant. Univariate analysis was performed using either Student's T-test or one-way ANOVA analysis of variance for continuous variables and Fischer's exact test for dichotomous variables. Outcome association with mechanism of injury, and level of injury were assessed using Kruskal-Wallis rank test. Variables achieving statistical significance on univariate analysis were included in a logistic regression model to assess variables predictive of survival. A receiver operating characteristic curve was determined to assess model fit of the regression model.

\section{Results}

During the 7-year period from January 2005 to December 2011, sixteen traumatic IVC injuries were identified at the Hospital Dr. Sotero del Rio, Santiago, Chile (mean age $=25.6+/-1.9$ years; ISS $=40.5+/-5.19 ; 87 \%$ male and $12 \%$ female). The mortality rate was $37.5 \%$ (6 patients). The mechanism of IVC injury was $56.2 \%$ gun shot wound (GSW) (9 patients), 37.5\% stab wound (SW) (6 patients), and $6.3 \%$ blunt injury (1 patient). In our series, the initial GCS was $11.8+/-1.1$. The number of associated injuries was $2.3+/-0.3$, including one or more of the following: superior mesenteric vasculature, gastric, duodenum, small bowel, large bowel, splenic, pancreatic, liver, lung, diaphragm, and cardiac. Univariate analysis did not show a significant increase in mortality with any associated injury (Table 1). Non-survivors were significantly more likely to be hypotensive in the

Table 3 Mortality by operative management (caval ligation versus simple repair)

\begin{tabular}{lcccc}
\hline $\begin{array}{l}\text { Operative } \\
\text { management }\end{array}$ & $\begin{array}{c}\text { Number of } \\
\text { patients }\end{array}$ & $\begin{array}{c}\text { Number of } \\
\text { deaths }\end{array}$ & ISS + & $\begin{array}{c}\text { Mortality } \\
\text { rate* }^{*}\end{array}$ \\
\hline IVC ligation & $6(37.5 \%)$ & 5 & $59+/-10.1$ & $83.3 \%$ \\
Simple repair & $10(62.5 \%)$ & 1 & $29.5+/-1.2$ & $16.6 \%$ \\
\hline
\end{tabular}

$+P$ value $=0.002$, Student's T-test.

${ }^{*} P$ value $=0.008$, Fischer's exact test. 
Table 4 Significant predictors of mortality by logistic regression

\begin{tabular}{lcccc}
\hline & OR & P value & $\begin{array}{c}\text { Confidence } \\
\text { interval }\end{array}$ & $\begin{array}{c}\text { Area under } \\
\text { ROC curve* }\end{array}$ \\
\hline Thoracotomy & 20 & 0.027 & $1.4-282.4$ & 0.81 \\
IVC ligation & 45 & 0.012 & $2.28-885.6$ & 0.86
\end{tabular}

Significant inverse predictors of mortality by logistic regression

\begin{tabular}{ccccc} 
OR & P value & $\begin{array}{c}\text { Confidence } \\
\text { interval }\end{array}$ & $\begin{array}{c}\text { Area under } \\
\text { ROC curve* }\end{array}$ \\
GCS & 0.6 & 0.026 & $0.46-0.95$ & 0.85 \\
\hline
\end{tabular}

${ }^{*}$ Area under ROC curve as a measure of model fit.

ER (ER MAP, $45.6+/-8.6 \mathrm{mmHg}$ vs. $76.5+/-25.4 \mathrm{mmHg}$, $\mathrm{p}=0.013)$, have a lower GCS $(8.1+/-4.1$ vs. $14+/-2.8$, $\mathrm{p}=0.004)$, have undergone thoracotomy in the OR $(83.3 \%$ vs. $16.6 \%, \mathrm{p}=0.024)$, have a shorter operative time $(105+/-59.8 \mathrm{~min}$ vs $189+/-65.3 \mathrm{~min}, \mathrm{p}=0.022)$, and have more severe injuries (ISS $60.3+/-3.5$ vs $28.7+/-$ 22.9, $\mathrm{p}=0.0006$ ) (Table 2).

Six patients $(37.5 \%)$ were managed with IVC ligation due to difficulty in obtaining adequate exposure and intraoperative hemodynamic instability, and ten patients (62.5\%) were managed with simple primary repair.

Caval ligation was significantly associated with increased mortality, with five out of the six patients managed with IVC ligation deceasing (mortality: 83.3\%) as opposed to one patient out of ten managed with primary repair (mortality: $16.67 \%, \mathrm{p}=0.008$ ) (Table 3 ). Upon logistic regression analysis, significantly increased odds of mortality were seen with the need to undergo thoracotomy for vascular control $(\mathrm{OR}=20,1.4-282.4, \mathrm{p}=0.027)$, and the use of caval ligation as operative management $(\mathrm{OR}=45,2.28-885.6, \mathrm{p}=0.012)$ (Table 4). GCS as a linear scale displayed an inverse relation with the risk of mortality expressed as a binary outcome. Upon linear regression analysis, GCS was a significant inverse predictor of mortality, $(\mathrm{p}=0.005)$ (Table 5). Upon logistic regression, a higher GCS was associated with significantly lower odds of mortality ( $\mathrm{OR}=0.6,0.46-0.95, \mathrm{p}=0.026$ ). ROC curves after logistic regression as a measure of model fit were 0.85 for GCS, 0.86 for caval ligation as operative management, and 0.81 for thoracotomy. In our cohort of patients, neither the mechanism of injury, nor the level of the IVC injury were significantly associated with an increase in mortality (Tables 6 and 7). No statistically significant differences existed among non-survivors

Table 5 GCS as a determinant of mortality by linear regression

\begin{tabular}{cccc}
\hline & Beta coefficient & P value* $^{*}$ & $\mathbf{R}^{\mathbf{2}+}$ \\
\hline GCS & -0.07 & 0.005 & 0.44 \\
Intercept & 1.27 & & \\
\hline
\end{tabular}

*Inverse relation between GCS and mortality by linear regression. $+\mathrm{R}$-squared as a measure of model fit.
Table 6 Mortality by mechanism of injury

\begin{tabular}{lcc}
\hline Mechanism & Number & Mortality rate $^{*}$ \\
\hline Blunt & $1(6.25 \%)$ & $0 \%$ \\
GSW & $9(56.25 \%)$ & $44.4 \%$ \\
SW & $6(37.5 \%)$ & $33.3 \%$ \\
Total & 16 & $37.5 \%$ \\
\hline
\end{tabular}

${ }^{*} \mathrm{P}=0.6$ (NS), Kruskal-Wallis analysis of variance rank test.

and survivors for $\mathrm{BE}$ on admission $(-19.4+/-8.3$ vs. $-12.7+/-6.1, \mathrm{p}=0.08)$, total number of associated injuries $(2.8+/-1.4$ vs. $1.9+/-0.9, \mathrm{p}=0.15)$, transfusional requirements expressed as packed red blood cells (PRBC) $(7.09+/-2.5$ vs. $7.23+/-2.7, \mathrm{p}=0.9)$, or time to surgical treatment $(19.5+/-6.9 \mathrm{~min}$ vs. $32.3+/-18.5 \mathrm{~min}$, $\mathrm{p}=0.13)$. Non-survivors mainly died on the operating table due to massive hemorrhage that was impossible to control operatively, with subsequent cardiac arrest. The mean hospital stay of survivors was $24.5+/-$ 14.2 days.

\section{Discussion}

Traumatic IVC injuries are a relatively rare event, occurring in only up to $5 \%$ of penetrating injuries and only up to $1 \%$ of blunt abdominal trauma [8]. Nonetheless, IVC trauma continues to present a formidable challenge to trauma surgeons, carrying an overall high mortality rate in spite of recent improvements in pre-hospital care, resuscitation upon arrival at a trauma center, diagnostic imaging, and timely surgical care. Our overall mortality rate for IVC trauma (37.5\%) is consistent with previous reports of IVC trauma mortality ranging from $21 \%$ to $56 \%$, with an overall mortality rate of $43 \%$ [1,5,7-10,14,16-18]. Previous reports have described predictors of mortality to be level of injury, shock on admission, timing of diagnosis to definitive management, blood loss, requirements for blood transfusions, associated injuries, ED thoracotomy, preoperative lactate and base deficits, ISS, and GCS [1,5,7-10,16-18]. In our cohort, we found statistically significant associations with the risk of mortality with hypotension upon arrival at the ER, thoracotomy,

Table 7 Mortality by number of injuries and IVC level of injury

\begin{tabular}{lccc}
\hline Level of injury & $\begin{array}{c}\text { Number } \\
\text { of injuries }\end{array}$ & $\begin{array}{c}\text { Number } \\
\text { of deaths }\end{array}$ & Mortality rate \\
\hline Infrarenal & $4(25 \%)$ & 1 & $25 \%$ \\
Pararenal & $4(25 \%)$ & 1 & $25 \%$ \\
Suprarenal & $5(31.2 \%)$ & 3 & $60 \%$ \\
Retrohepatic & $1(6.25 \%)$ & 1 & $100 \%$ \\
Intrapericardial & $2(12.5 \%)$ & 0 & $0 \%$ \\
& P value $=0.8(\mathrm{NS})^{*}$ & & P value $=0.3($ NS) \\
\hline
\end{tabular}

*Kruskal-Wallis analysis of variance rank test. 
operative time, injury severity expressed as ISS, and GCS. There was a trend towards ascending mortality as the level of injury approached the heart, however we were unable to find a statistically significant relation between level of injury and mortality. This is likely due to the small size of our cohort, and the fact that the two patients in our series with intra-perdicardial lesions, both survived. Upon regression analysis, significant predictors of mortality were thoracotomy, IVC ligation as operative management, and GCS.

GCS as an independent predictor of mortality in IVC trauma has been previously described in a patient population with a higher incidence of blunt trauma (28\%) than our patient cohort (6.3\%) [5]. Nonetheless, in our patient cohort presenting with a high incidence of penetrating IVC trauma (93.7\%), logistic regression confirmed GCS is significantly associated with mortality. In our cohort, patients did not sustain major head injuries, thus the significant association GCS demonstrated with mortality likely reflects substantial hemodynamic compromise, as has been previously proposed [5].

The other determinants of mortality in our regression model were thoracotomy and to have undergone IVC ligation instead of simple suture repair. The use of thoracotomy to obtain vascular control likely suggests more extensive vascular injuries, which is consistent with the fact non-survivors had significantly more severe injuries as expressed by a higher ISS. Significantly better survival has been previously described in IVC injuries treated with IVC ligation [1], and thus our results must be interpreted with caution. However, in our cohort IVC ligation was utilized as a salvage method to treat vascular injuries not amenable to primary repair or when the surgical team faced difficulty in obtaining adequate exposure in a patient at risk of exsanguination. Patients treated with IVC ligation had more severe injuries as reflected by a significantly higher ISS (Table 3 ).

Our study has several limitations, including our small sample size and its retrospective nature. However our results are relevant as we confirm GCS as a predictor of mortality in patients with traumatic IVC injuries. This study, along with others, point to the relevance of GCS as a predictor of mortality in patients with IVC trauma, of both blunt and penetrating etiology. Further prospective studies are needed to confirm the validity of GCS along with other previously described determinants of mortality in IVC trauma. Likewise, management protocols need be established to decrease the high mortality rate that is still seen with traumatic IVC injuries, which has not improved in spite of improved resuscitation and pre-hospital care.

\section{Conclusions}

In spite of being a relatively rare event, trauma related IVC injuries present a formidable challenge to the trauma surgeon, with a high overall mortality rate of $43 \%$, which has not changed in recent years despite vast improvements in pre-hospital transport time and care, hospital resuscitation and surgical critical care. Our results confirm GCS is an independent predictor of mortality in IVC trauma. Other significant determinants of mortality in our cohort were the use of thoracotomy, and the use of IVC ligation as operative management. Further prospective studies are needed to confirm the validity of the described determinants of mortality in IVC trauma. Management protocols need be established to decrease the high mortality rate still carried by traumatic IVC injuries.

\section{Abbreviations \\ IVC: Inferior vena cava; GCS: Glasgow coma scale; ISS: Injury severity score: ED: Emergency department; OR: Operating room; BE: Base excess; MAP: Mean arterial pressure; SBP: Systolic blood pressure; DBP: Diastolic blood pressure; IRIVC: Infra-renal vena cava; PRIVC: Para-renal vena cava; SRIVC: Supra-renal vena cava; RHIVC: Retro-hepatic vena cava; SHIVC: Supra-hepatic vena cava; ROC: Receiver operator curve; NS: Not significant.}

\section{Competing interests}

The author's declare that they have no competing interests.

\section{Authors' contributions}

All authors: 1) have made substantial contributions to conception and design, or acquisition of data, or analysis and interpretation of data; 2) have been involved in drafting the manuscript or revising it critically for important intellectual content; 3 ) have given final approval of the version to be published. MC: Study conception and design, acquisition of data, analysis and interpretation of data, drafting of manuscript. JR: Study conception and design, acquisition of data, analysis and interpretation of data, drafting of manuscript. AF: Study conception and design, acquisition of data, critical revision of manuscript. IA: Study conception and design, acquisition of data, analysis and interpretation of data, critical revision of manuscript. All authors have read and approved the final manuscript.

\section{Author details}

${ }^{1}$ Adult Emergency Services, Surgery, Hospital Dr. Sotero del Rio, Concha y Toro, 3459 Puente Alto, Santiago, Chile. ${ }^{2}$ Vascular Surgery, Hospital Dr. Sotero del Rio, Concha y Toro, 3459 Puente Alto, Santiago, Chile.

Received: 1 October 2013 Accepted: 26 December 2013

Published: 29 December 2013

\section{References}

1. Kuehne J, Frankhouse J, Modrall G, Golshani S, Aziz I, Demetriades D: Determinants of survival after inferior vena cava trauma. Am Surg 1999, 65(10):976-981.

2. Jackson MR, Olson DW, Beckett WC Jr: Abdominal vascular trauma: a review of 106 injuries. Am Surg 1992, 58:622-626.

3. Ombrellaro MP, Freeman MB, Stevens $S L$, et al: Predictors of survival after inferior vena cava injuries. Am Surg 1997, 63:178-183.

4. Leppaniemi AK, Savolainen HO, Salo JA: Traumatic inferior vena caval injuries. Scand J Thorac 1994, 28:103-108.

5. Huerta S, Bui T, Nguyen T, Banimahd F, Porral D: Predictors of mortality and management of patients with traumatic inferior vena cava injuries. Am Surg 2006, 72(4):290-296.

6. Burch JM, Feliciano DV, Mattox KL: The atriocaval shunt. Facts and fiction. Ann Surg 1988, 207:555-568.

7. Klein SR, Baumgartner FJ, Bongard FS: Contemporary management strategy for major inferior vena caval injuries. J Trauma 1994, 37:35-41.

8. Kudsk KA, Bongard F, Lim RX Jr: Determinants of survival after vena caval injury. Analysis of a 14year experience. Arch Surg 1984, 119:1009-1012. 
9. Rosengart M, Smith D, Melton S, May A: Prognostic factors in patients with inferior vena cava injuries. Am Surg 1999, 65(9):849-856.

10. Turpin I, State D, Schwartz A: Injuries to the inferior vena cava and their management. Am J Surg 1977, 134:25-32.

11. Wilson RF, Wiencek RG, Balog M: Factors affecting mortality rate with iliac vein injuries. J Trauma 1990, 30:320-323.

12. Buckman RF, Pathak AS, Badellino MM, et al: Injuries of the inferior vena cava. Surg Clin North Am 2001, 81:1431-1447.

13. Blaisdell FW, Lim RC Jr: Liver resection. Major Probl Clin Surg 1971, 3:131-145.

14. Bricker DL, Morton JR, Okies JE, et al: Surgical management of injuries to the vena cava: changing patterns of injury and newer techniques of repair. J Trauma 1971, 11:722-735.

15. Brown RS, Boyd DR, Matsuda T, et al: Temporary internal vascular shunt for retrohepatic vena cava injury. J Trauma 1971, 11:736-737.

16. Byrne DE, Pass HI, Crawford FA Jr: Traumatic vena caval injuries. Am I Surg 1980, 140:600-602.

17. Graham JM, Mattox KL, Beall AC Jr, et al: Traumatic injuries of the inferior vena cava. Arch Surg 1978, 113:413-418.

18. Millikan JS, Moore EE, Cogbill TH, et al: Inferior vena cava injuries: a continuing challenge. J Trauma 1983, 23:207-212.

doi:10.1186/1749-7922-8-59

Cite this article as: Cudworth et al:: GCS as a predictor of mortality in patients with traumatic inferior vena cava injuries: a retrospective review of 16 cases. World Journal of Emergency Surgery 2013 8:59.

\section{Submit your next manuscript to BioMed Central and take full advantage of:}

- Convenient online submission

- Thorough peer review

- No space constraints or color figure charges

- Immediate publication on acceptance

- Inclusion in PubMed, CAS, Scopus and Google Scholar

- Research which is freely available for redistribution 